$\begin{array}{ll}\begin{array}{l}\text { Cell division } \\ \text { Institute launched to } \\ \text { plunder life sciences } \\ \text { for space travel } \\ p 878\end{array} & \begin{array}{l}\text { Cold draft } \\ \text { Polar organisms } \\ \text { line up for genome } \\ \text { sequencing } \\ \text { p880 }\end{array}\end{array}$

\title{
Draft guidelines ease restrictions on use of genome sequence data
}

\section{Carina Dennis}

Researchers working on large-scale publicly funded genome-sequencing projects must release their data as soon as possible, without imposing restrictions on the use of the information, say guidelines from two of the main funders of such work.

The US National Human Genome Research Institute (NHGRI) this week issued a draft revision to its policy on the use of data from large-scale genome projects. Existing rules prohibit users from publishing a wholegenome analysis before the sequencers' initial publication on the complete genome. "That restriction will be removed and will not be present in any other genome databases that we support," says the institute's director, Francis Collins.

The move follows discussions at a meeting of sequencers, bioinformatics researchers and journal editors last month in Fort Lauderdale, Florida, aimed at resolving disagreements over data access. The revision is expected to be approved by the institute's advisory council in May.

The Wellcome Trust, the London-based medical charity that convened the meeting, will also apply similar rules to the large-scale genome-sequencing projects for which it provides funding. Both organizations may also extend the rules to other large-scale

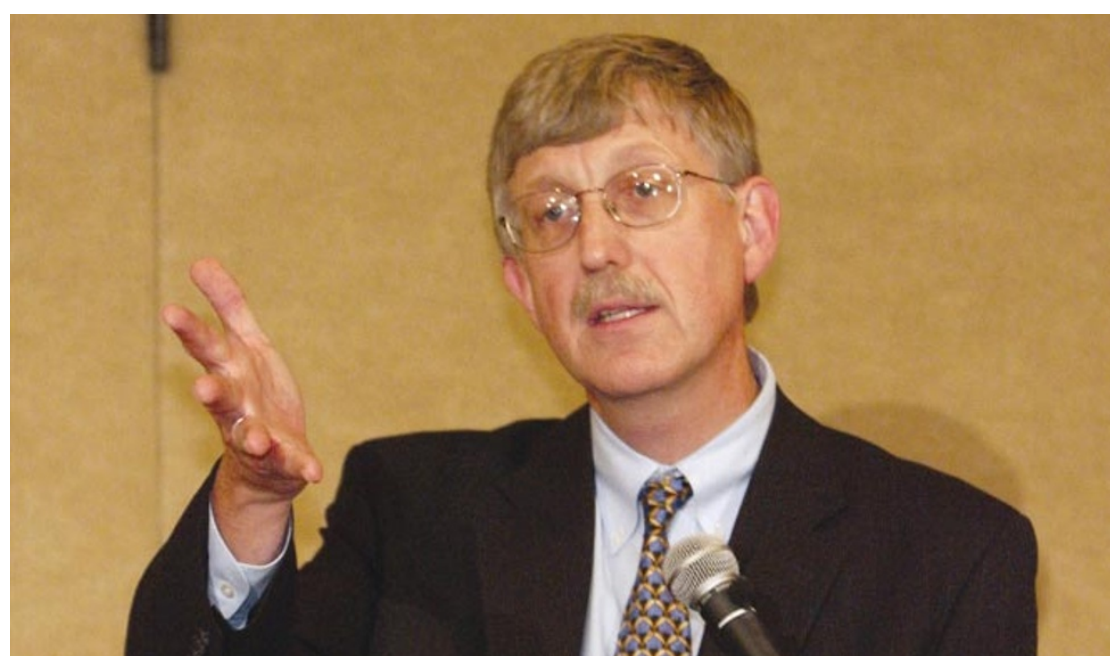

Francis Collins supports the publication of genome analyses before the sequence is completed.

ventures, such as protein-structure projects and analyses of gene expression.

The NHGRI's guidelines say users should acknowledge that "sequence producers have a legitimate interest in publishing peerreviewed reports" about their sequence, and that "the entire scientific community can also help ensure that the system works fairly". They are an extension of the Bermuda Principle — the 1996 agreement between the leaders of the Human Genome Project to make sequence data available without restrictions within 24 hours.

The move is likely to find favour with bioinformatics researchers, who use the sequence, but sequence producers may worry about being scooped. "Some groups may lack the integrity to play gentlemen's cricket," says Richard Gibbs, director of the Human Genome Sequencing Center at

\section{Mixed results win HIV vaccine a guarded response}

Hannah Hoag, Washington

Statisticians are urging caution over intriguing results from clinical trials of an HIV vaccine, which suggest that some ethnic groups may benefit from the drug.

Biotechnology company VaxGen announced the results of its AIDSVAX trials on 24 February. The overall results were disappointing, with only a $3.8 \%$ reduction in infection among those who were vaccinated compared with those who received a placebo. But the vaccine shows more positive results for certain ethnic subgroups, the company claims. Among black volunteers, for example, only $2 \%$ of those who received AIDSVAX became infected with HIV, compared with $8 \%$ of those who received a placebo.

"The subset analysis showed surprising and provocative results in minorities," says Anthony Fauci, director of the National Institute of Allergy and Infectious Diseases (NIAID).

But of the 5,009 participants in the study, only 314 were black, and some researchers warn against drawing premature conclusions. "Subgroup analysis has to be seen as more exploratory," says biostatistician Steven Self of the Fred Hutchinson Cancer Research Center in Seattle, Washington. "Over the next few months, the detailed analysis will show whether there is an underlying biology that could explain the results."

VaxGen, which is based in Brisbane, California, plans to investigate factors such as age, sex and behaviour among the subgroups to see if something other than the vaccine can explain the results. It says that a more detailed analysis of the trial's results should be available by the end of March.

Several other possible vaccines may be less than five years away from large-scale clinical trials. The NIAID is developing two candidates for testing, and drug company Merck, based in Whitehouse Station, New Jersey, is also working on a vaccine. 
Baylor College of Medicine in Houston.

The team working on the malaria parasite Plasmodium falciparum was angered when other researchers tried to publish studies of sequence data before the project was complete (see Nature 405, 601-602; 2000). But Collins believes this risk is a small price to pay to ensure the immediate release of data. "We will be scooped on a few occasions," agrees Jonathan Eisen of The Institute for Genome Research in Rockville. "We'll just have to deal with it."

The guidelines could also hamper international collaborations. "While we as scientists are willing to release the data, the funding agencies in Japan may not support data release without restrictions," says Yoshiyuki Sakaki of the RIKEN Genomic Sciences Center in Yokohama City, Japan. "Chinese agencies will face a dilemma," adds Huanming Yang, head of the Beijing Genomics Institute. "Why should they invest the money if they can get data for free from the United States?"

But some question whether there will be a rush to publish ahead of the sequence centres. "I would much rather the annotation be done at the sequencing centre, rather than a third party who doesn't know how the data were generated," says Sean Eddy, a bioinformatician at Washington University School of Medicine in St Louis, Missouri. "We can't be biting the hand that feeds us."

\section{Physicists fail to find saving grace for falsified research}

Philip Ball

In the furore that followed last year's revelation that Jan Hendrik Schön had fabricated data in a string of high-profile papers, one question remained unanswered: was there a nugget of truth in any of his reported findings? Two teams have now attempted to replicate some of Schön's key results, and find that little of use can be salvaged from them.

The two groups recreated studies by Schön, who was based at Bell Laboratories in Murray Hill, New Jersey, on molecular fieldeffect transistors. The papers that they revisited featured examples of 7 of the 16 different types of data falsification or fabrication of which Schön was found guilty last October ${ }^{1}$.

Field-effect transistors - electronic devices that can switch and amplify currents - are the workhorses of silicon circuits. Schön claimed to have observed transistorlike behaviour in a layer of an organic compound, just one molecule thick, sandwiched between two metal electrodes. This suggested that the size of transistors, and thus of integrated circuits, could be hugely reduced.

Teams of physicists at the Delft University of Technology in the Netherlands and IBM's Thomas J. Watson Research Center in Yorktown Heights, New York, have now investi- gated devices based on Schön's design ${ }^{2,3}$. Both groups followed the methods in his papers: the electrodes were made from thin layers of gold, between which rod-like organic molecules capped with gold-binding chemical groups provided a conducting pathway.

Neither group obtained the results recorded by Schön. Jeong-O. Lee and colleagues at Delft, for example, say that their devices were unreliable from the outset. Of more than 1,000 prepared, many were shortcircuited - the current simply flowed between the two electrodes, heedless of the intervening layer of molecules. Only in $5-16 \%$ of devices did the current seem to flow through the molecular layer. Even then, the devices quickly degraded.

Coming from two of the world's most experienced molecular-electronics labs, the results imply that the approach is fundamentally flawed. But the new studies have highlighted requirements for making similar molecular transistors, such as better methods for purifying the components. "There is no scientific reason to lose faith in the tremendous promise of the field," insists Cherie Kagan, a member of the IBM group.

1. Brumfiel, G. Nature 419, 419-421 (2002).

2. Lee, J.-O. et al. Nano Lett. 3, 113-117 (2003).

3. Kagan, C. R. et al. Nano Lett. 3, 119-124 (2003).

\section{NASA seeks inspiration from microscopic views of life}

\section{Jonathan Knight, San Francisco}

The space-shuttle programme may be on hold, but NASA researchers are still dreaming of the future. Ten days after the Columbia broke apart on re-entry, scientists gathered at the University of California, Los Angeles (UCLA), to discuss the development of futuristic spacecraft modelled on living cells.

The day-long event, held on 10 February, inaugurated the Institute for Cell Mimetic Space Exploration, which is funded mainly by a ten-year, US\$30-million grant from NASA. The agency hopes that the institute's 15 principal investigators, housed at UCLA and several other southwestern universities, will come up with biology-inspired devices that could facilitate space travel 30 years from now.

It's an open-ended goal, admits Harry Partridge, an administrator at the NASA Ames Research Center in Moffett Field, California. "Instead of asking what do we need and how do we get there, this asks what is possible and what we can do with what we come up with," he says.
Most of the research groups are exploring basic cellular processes that might later be scaled up. Biomedical engineer Carlo Montemagno's group at UCLA, for example, is developing microscopic sacks of biological reagents - which the group calls 'biobugs' - that propel themselves, amoeba-like, across a substrate. The sacks will include growing filaments of actin, which normally make up the skeletons of living cells. According to Montemagno's theory, the biobags will move at several micrometres per minute by extending an actin filament and pulling themselves along it.

Montemagno says that the goal is to endow the biobugs with the ability to sniff out and move towards specific substances, in much the same way that nerve tips grow towards chemical signals in the body. Biobugs could be dispatched en masse to search a spaceship for chemical or biological contamination, Montemagno suggests.

Other groups are copying different systems from the book of life, such as networks that gather sunlight, transmit

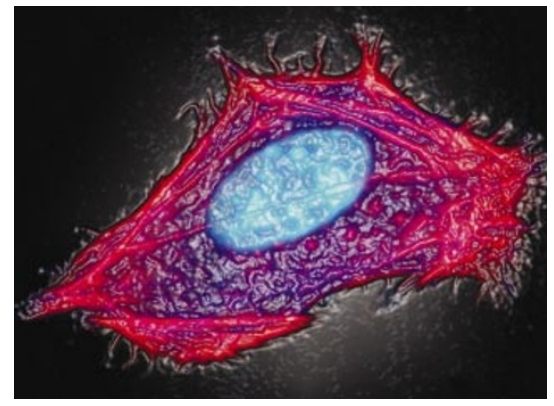

Cellular example: NASA researchers hope that cell biology will inform future space travel.

information through chemical signals and repair structural damage.

The inaugural event was planned before the Columbia disaster, and NASA administrators decided to hold it as scheduled. "In the spirit of exploration, things must go on," says the director of the institute Chih-Ming Ho, an aerospace engineer at UCLA.

www.cmise.ucla.edu 